\title{
FLEXIBILITY OF THE RETENTIVE ARM OF ACETAL RESIN CLASP VERSUS CAST CLASPS- AN IN VITRO STUDY
}

\section{Shruti Lakhanpal, Neelima Menon $\mathrm{S}^{*}$ \\ PSM Dental College, Akkikkavu Thrissur, Kerala - 680519}

\begin{abstract}
Purpose: To compare and evaluate the flexibility of retentive terminal of acetal resin clasp and cobalt chromium clasp
\end{abstract}

Methodology: twenty acetal resin and cobalt chromium clasps were used over an undercut of 0.5 $\mathrm{mm}$. The flexibility of the clasps were measured using a tensometer and the retentive force was recorded in Newtons. The data were subjected to statistical analysis using Student's t test.

Results: The mean force to cause a deflection of $0.5 \mathrm{~mm}$ was 4.53 for acetal resin clasp and 18.69 for cobalt chromium clasp. The mean flexibility of acetal resin clasp was significantly higher than that of cobalt chromium clasp.

Conclusion: Within the limitations of the study, it can be concluded that the retentive terminal of acetal resin clasp when compared with cobalt chromium clasp exhibits displacement within the range of force required to dislodge circumferential clasp

Keywords: Acetal Resin Clasp, Cast clasp

\section{INTRODUCTION:}

Restoration of esthetics is an important factor to consider in the fabrication of a removable partial denture (RPD). ${ }^{1}$ Several types of polymers and metal alloys have been used in RPD construction. Frequently, RPD clasps made from the same alloy as the metal framework. The most common alloys used for clasps are cobalt-chromium (Co-Cr) alloy and gold and titanium alloys, although these may be unesthetic. ${ }^{2}$ Some strategies can be used to optimize aesthetic results in RPDs, such as attachment systems ${ }^{3}$ RPD with a rotational path of insertion, ${ }^{4}$ aesthetic clasp designs ${ }^{5}$ and aesthetic materials for making clasps. ${ }^{6-}$ ${ }^{9}$ Polyoxymethylene (POM), also known as acetal resin, has been used as an alternative denture base and denture clasp material since 1986 and was promoted, primarily, for superior esthetics. ${ }^{6}$ Acetal resins are formed by the polymerization of formaldehyde. ${ }^{11}$ The homopolymer (POM) is a chain of alternating methyl groups linked by an oxygen molecule. ${ }^{10}$ Because of its biocompatibility, it was considered as an RPD framework material for patients with allergic reactions to $\mathrm{Co}-\mathrm{Cr}$

*Corresponding author:

Email:drneelimaprosthodontist@gmail.com

http://dx.doi.org/10.20530/IJTA 33 90-95

ISSN 2320-138X (C) 2016 alloys. ${ }^{6}$ It is reported to have a sufficiently high resilience and modulus of elasticity to allow its use in the manufacture of retentive clasps, connectors, and support elements for RPDs. ${ }^{6,10}$

Several investigations have determined the properties of the materials used to fabricate RPD clasps. Investigators have considered the long-term effectiveness of the clasps and the effects that the clasp might have on the abutment teeth. ${ }^{11,12,13}$ A clasp arm design producing less stress is important for predictable long-term use of an RPD. Three factors-clasp material, clasp form, and the amount of undercut-affect the design of a clasp arm. ${ }^{14}$ Clasp form involves the elements of length, curvature, cross-sectional dimension, and taper. Clasp form is associated with stress distribution, which affects fatigue and permanent deformation. ${ }^{15}$ Poor fit may cause the decrease of retention and failure of RPD function. ${ }^{16}$ However, the mechanical properties of a clasp material are generally determined by the alloy used. ${ }^{17}$

Metals and metal alloys undergo permanent deformation and fatigue when exposed to repeated stress. ${ }^{18}$ The fatigue of a denture clasp is based on the repeated deflection of the clasp during insertion and removal of the RPD over the undercuts of the teeth. ${ }^{2}$ 


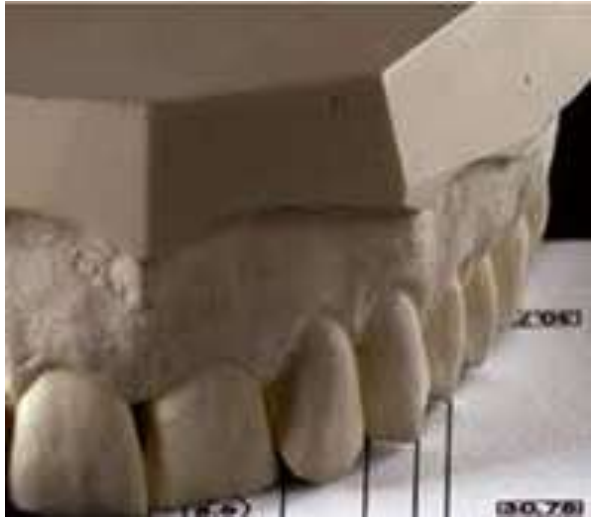

Fig :1 Hemiarch stone cast of a partial edentulous situation was fabricated

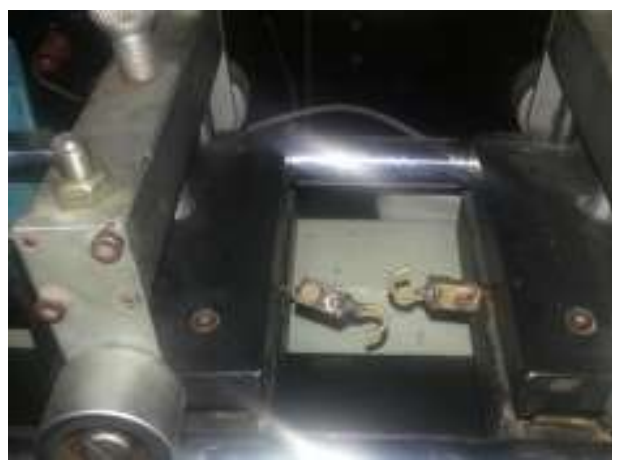

Fig3: Two hooks were custom fabricated to fit the two testing arms of the tensometer to engage the reciprocal and retentive terminal of clasp assembly

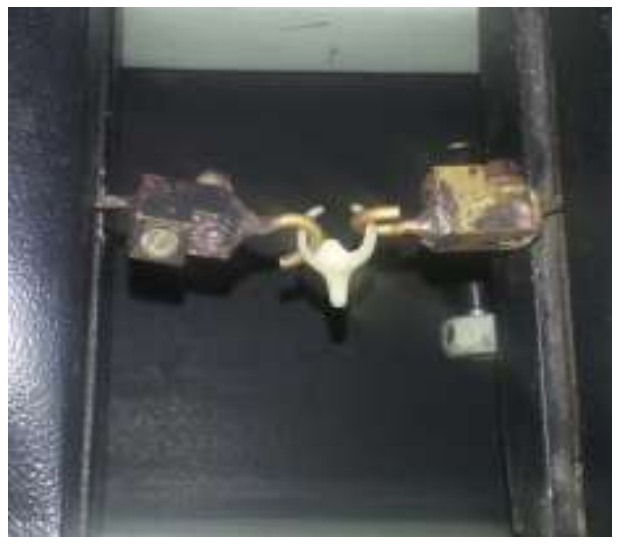

Figure: 5 Flexibility of acetal resin clasp arm being tested in tensometer

Although extensive work has been performed to determine the properties of a variety of materials used for RPD clasps, yet the review of literature did not reveal enough studies with regard to the flexibility of retentive terminal of cast clasp and acetal resin clasp.

Hence, this study was undertaken to evaluate

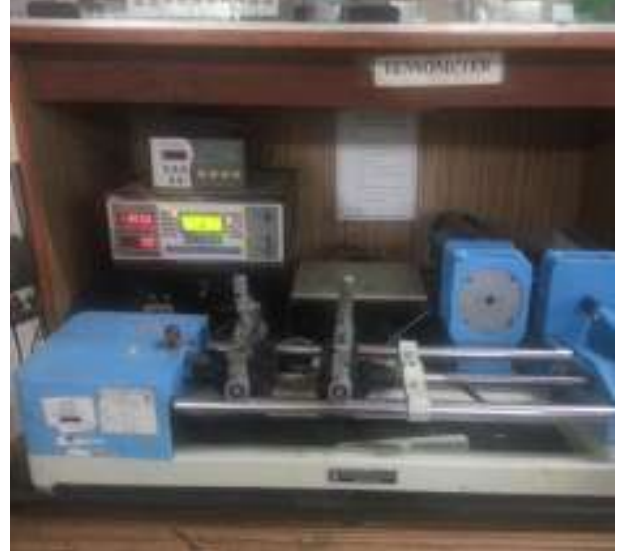

Fig 2: Tensometer

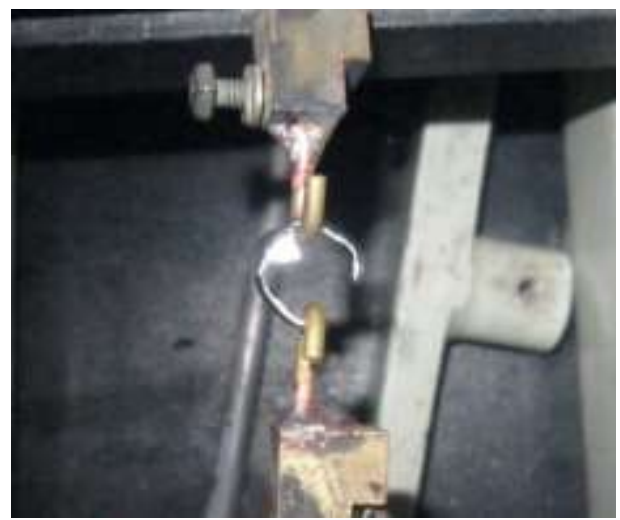

Fig4: Flexibility of cast clasp arm being tested in tensometer

and compare the flexibility of the terminal third of the retentive arm of acetal resin clasp and cast

\section{MATERIALS \& METHODS}

Ten circumferential cast clasps (cobalt chromium) fabricated from wax pattern on molar tooth with undercut of $0.5 \mathrm{~mm}$., Ten circumferential acetal resin clasps fabricated from wax pattern on molar tooth with undercut of $0.5 \mathrm{~mm}$, Ney's Surveyor, Tensometer (Fig. 1), Hemiarch stone cast with $0.5 \mathrm{~mm}$ undercut (Dental stone: Kalabhai Karson Pvt Limited)

A hemiarch stone cast of a partial edentulous situation was fabricated. Cast was surveyed and the height of contour was marked. An undercut of $0.002 "(0.5 \mathrm{~mm})$ was marked from the survey line. Rest seat and guide plane was prepared. The cast was duplicated and refractory cast was obtained after block out. Ten prefabricated wax patterns of circumferential clasps were used to fabricate 


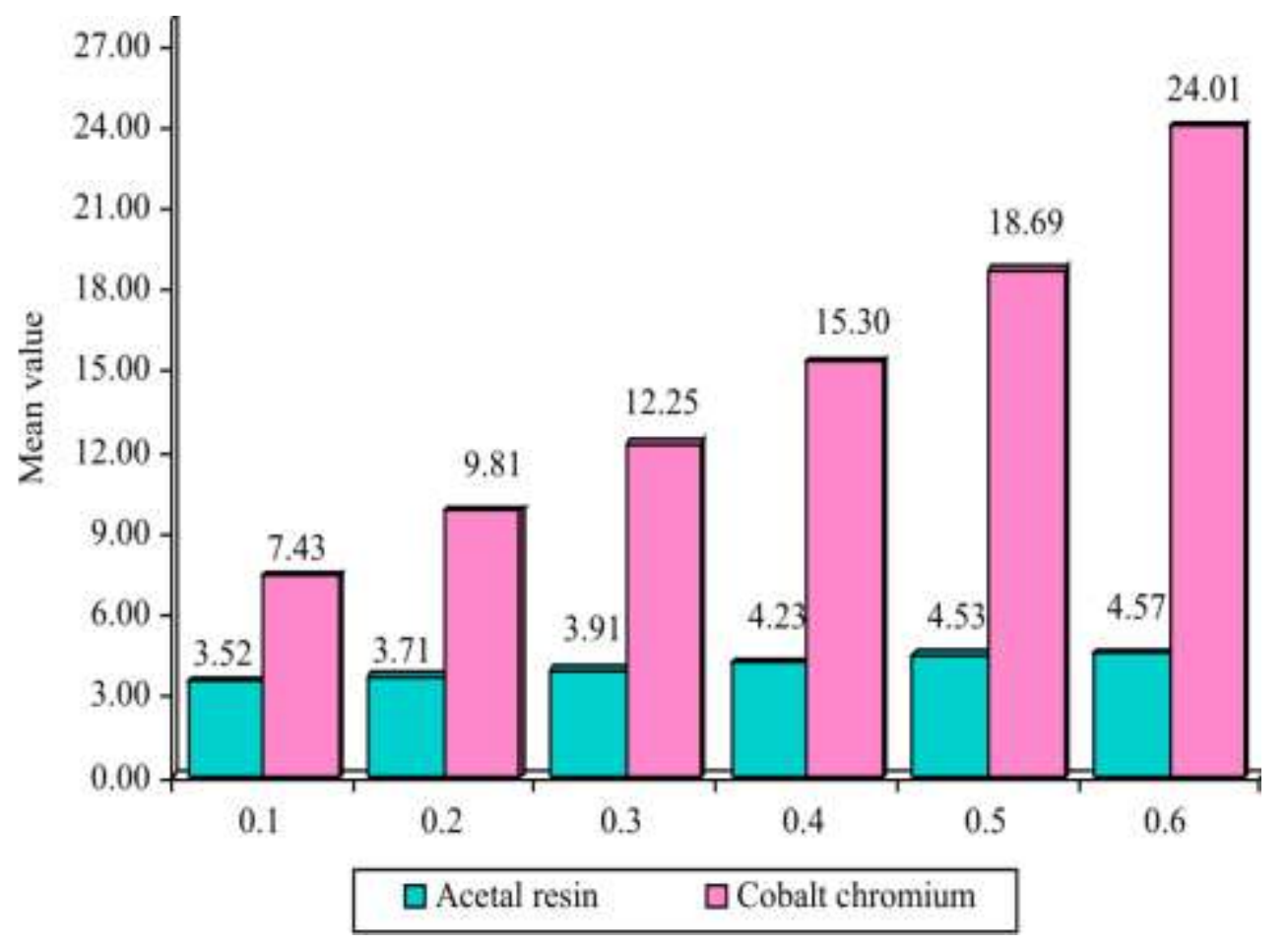

Graph1.The bar diagram represents the comparison of acetal resin and cobalt chromium clasps in relation to the deflections $(\mathrm{mm})$ when forces $(\mathrm{N})$ are applied.

cast clasps of Cobalt chromium and acetal resin clasps. All specimens were fabricated using standard wax patterns of circumferential clasps to standardize the groups. Therefore, acetyl resin and $\mathrm{Co}-\mathrm{Cr}$ clasps had the same thickness.

These twenty clasps were used as samples for the study.

Each clasp was then subjected to a tensile load using tensometer at the terminal third of the retentive arm, to assess its flexibility.

Two custom designed hooks were fabricated to engage the reciprocal and the retentive terminal of clasp assembly and engage it to the two testing arms of the tensometer.

Tensile loads were applied onto the retentive terminal using the tensometer at the crosshead speed of $1 \mathrm{~mm} / \mathrm{min}$ to determine the flexibility of retentive terminal.

The flexibility of the retentive terminal was measured using tensometer at the crosshead speed of $1 \mathrm{~mm}$ per minute and force was gradually increased from 0- $26 \mathrm{~N}$. In an earlier study it was observed that a force of 3 to 26 Newton ${ }^{19}$ would act on a cast clasp and hence the clasps in this study were subjected to a force of 0 to 26 Newton.

Student's t test was applied at 0.05 level of significance, Null Hypothesis: There is no significant difference in the mean values recorded from the two clasps; Alternate Hypothesis: There is a significant difference in the mean values recorded from the two clasps.

\section{RESULTS}

The null hypothesis is therefore rejected as the difference in the mean deflections of cobalt chromium and acetal resin clasp is statistically significant

Retentive clasp arms must be capable of flexing and returning to their original form and should retain an RPD satisfactorily. The tooth should not be unduly stressed or permanently distorted during service and should provide esthetic results. ${ }^{12}$

This study was designed to compare the flexibility of acetal resin and cobalt chromium clasp using a tensometer.

The results reveal that the difference in the flexibility of acetal resin and cobalt chromium 
Table 1: Depicts the comparison of acetal resin and cobalt chromium clasps in relation to the deflections $(\mathrm{mm})$ when forces $(\mathrm{N})$ are applied to test samples using t test.

\begin{tabular}{|l|l|c|c|c|c|c|}
\hline \multirow{2}{*}{ Displacement } & Clasp & Mean & SD & SE & t-value & P-value \\
\hline 0.1 & Acetal resin & 3.52 & 0.30 & 0.10 & -8.0950 & $0.00001^{*}$ \\
\cline { 2 - 5 } & Cobalt chromium & 7.43 & 1.50 & 0.47 & & \\
\hline 0.2 & Acetal resin & 3.71 & 0.19 & 0.06 & -11.0478 & $0.00001^{*}$ \\
\cline { 2 - 5 } & Cobalt chromium & 9.81 & 1.74 & 0.55 & & \\
\hline 0.3 & Acetal resin & 3.91 & 0.50 & 0.16 & -11.4590 & $0.00001^{*}$ \\
\cline { 2 - 5 } & Cobalt chromium & 12.25 & 2.25 & 0.71 & & \\
\hline 0.4 & Acetal resin & 4.23 & 0.23 & 0.07 & -12.0227 & $0.00001^{*}$ \\
\cline { 2 - 5 } & Cobalt chromium & 15.30 & 2.90 & 0.92 & & \\
\hline 0.5 & Acetal resin & 4.53 & 0.35 & 0.11 & -17.3006 & $0.00001^{*}$ \\
\cline { 2 - 4 } & Cobalt chromium & 18.69 & 2.56 & 0.81 & & \\
\hline 0.6 & Acetal resin & 4.57 & 0.25 & 0.08 & -32.9561 & $0.00001^{*}$ \\
\cline { 2 - 4 } & Cobalt chromium & 24.01 & 1.86 & 0.59 & & \\
\cline { 2 - 4 } & & & & & & \\
\hline
\end{tabular}

clasp was statistically significant.

The mean flexibility of the retentive terminal of acetal resin clasp was higher than cobalt chromium clasp. Acetal resin has a relatively high proportional limit with little viscous flow, enabling it to behave elastically over a large enough range to be used as a material for clasp fabrication. ${ }^{10}$

With the increased requirements of esthetics, more patients are requesting that dentists conceal RPD clasps by placing them closer to the gingival, where the undercuts tend to be larger. The stiffness of $\mathrm{Co}-\mathrm{Cr}$ clasps makes them unsuitable for placement in larger undercuts due to unacceptable stresses on the abutments. ${ }^{11}$ One property of acetal resins that has created interest for use in RPDs is the low modulus of elasticity, which allows for their use in larger retentive undercuts than recommended for $\mathrm{Co}-\mathrm{Cr}$ alloys. ${ }^{10}$ This may be advantageous in clinical situations in which esthetics and/or periodontal health are priorities. $^{13}$

The results of the present study revealed that the flexibility of acetal resin clasp was $4.53 \mathrm{~N}$ and cobalt chromium clasp was $18.8 \mathrm{~N}$. The mean flexibility of acetal resin claps was five times greater than cobalt chromium clasp.

Table 2 depicts the mean force required to bring about deflection to flex over the height of contour.The results revealed that the mean force required to displace a cobalt chromium clasp from $0.25 \mathrm{~mm}$ undercut was 9.81 and

Table 2. Represents the mean force required to bring about deflection to flex over the height of contour

\begin{tabular}{lll}
\hline $\begin{array}{l}\text { Undercut } \\
\text { depth }\end{array}$ & $\begin{array}{l}\text { Cobalt } \\
\text { chromium } \\
\text { clasp }\end{array}$ & $\begin{array}{l}\text { Acetal resin } \\
\text { clasp }\end{array}$ \\
\hline $0.25 \mathrm{~mm}$ & 9.81 & 3.71 \\
$0.50 \mathrm{~mm}$ & 18.69 & 4.83 \\
\hline
\end{tabular}




\subsection{1 for an acetal resin clasp.}

Ahmad et $\mathrm{al}^{20}$ found that 4.77-N retention was required to dislodge a Co-Cr clasp from a 0.25$\mathrm{mm}$ undercut. Frank and Nicholls ${ }^{21}$ concluded that 300 to $750 \mathrm{~g}(2.94 \mathrm{~N}$ to $7.35 \mathrm{~N})$ represented an acceptable amount of retention for a bilateral distal ex- tension RPD.

From this study it was observed that the retentive terminal of acetal resin clasp when compared with cobalt chromium clasp had flexibility within this range of force required to dislodge circumferential clasp.

Suggesting that acetal resin is a superior material than cobalt chromium because it assists in overcoming the poor esthetics of anterior clasping and demonstrates greater flexibility therefore, resulting in reduced loads on the abutment teeth may not be adequate to change the choice of the material.

The lower retention provided by acetal resin clasps should be considered in clinical use. Further research using deeper undercuts, thicker retentive clasp arms and different clasp designs is recommended to provide additional information for acetyl resin RPD clasps.

\section{CONCLUSION}

The mean force required to produce a deflection of $0.5 \mathrm{~mm}$ for acetal resin clasp was $18.8 \mathrm{~N}$ and for cobalt chromium clasp was $4.53 \mathrm{~N}$

The mean flexibility of acetal resin clasp was five times than that of cobalt chromium clasp for $0.5 \mathrm{~mm}$ undercut.

Hence, the retentive terminal of acetal resin clasp when compared with cobalt chromium clasp exhibited displacement within the range of force required to dislodge circumferential clasp.

\section{REFERENCES}

1. Invisible partial dentures available now. Br Dent J; 2014 Feb 21;216(4):203-203. Available from: http://dx.doi.org/10.1038/sj.bdj.2014.136

2. Deflection fatigue of cobalt-chromium, titanium, and gold alloy cast alloy cast denture clasp Vallittu, P.K. and Kokkonen, K. J. Prosthet. Dent. (1995) 74 (4), 412-419. International Journal of Fatigue; 1997 Mar;19(3):265-6. Available from: http://dx.doi.org/10.1016/s0142-1123(97)83292-6
3. Şakar O. Esthetic Solutions for Removable Partial Dentures. Removable Partial Dentures; 2016;12334. Available from: http://dx.doi.org/10.1007/9783-319-20556-4

4. Jacobson TE. Satisfying Esthetic Demands with Rotational Path Partial Dentures. The Journal of the American Dental Association; 1982 Sep;105(3):4605. Available from: http://dx.doi.org/10.14219/jada.archive.1982.0346

5. Turner JW, Radford DR, Sherriff M. Flexural Properties and Surface Finishing of Acetal Resin Denture Clasps. Journal of Prosthodontics ;8(3):188-95. Available from: http://dx.doi.org/10.1111/j.1532849x.1999.tb00034.x

6. Şakar O. Esthetic Solutions for Removable Partial Dentures. Removable Partial Dentures ; 2016;12334. Available from: http://dx.doi.org/10.1007/9783-319-20556-4 12

7. Tse T, Edward. A comparison of the retentive characteristics of cast titanium and cobaltchromium clasps. The University of Hong Kong Libraries; Available from: http://dx.doi.org/10.5353/th b3195424

8. Wu JC, Latta GH, Wicks RA, Swords RL, Scarbecz M. In vitro deformation of acetyl resin and metal alloy removable partial denture direct retainers. The Journal of Prosthetic Dentistry; 2003 Dec;90(6):586-90. Available from: http://dx.doi.org/10.1016/j.prosdent.2003.09.020

9. Fitton JS, Davies EH, Howlett JA, Pearson GJ. The physical properties of a polyacetal denture resin. Clinical Materials [Internet]. Elsevier BV; 1994 Jan;17(3):125-9. Available from: http://dx.doi.org/10.1016/0267-6605(94)90135-x

10. Bridgemana JT, Marker VA, Hummel SK, Benson BW, Pace LL. Comparison of titanium and cobaltchromium removable partial denture clasps. The Journal of Prosthetic Dentistry; 1997 Aug;78(2):187-93.Availablefrom: http://dx.doi.org/10.1016/s0022-3913(97)70124-0

11. Duration of induction melting of cobaltchromium alloy and its effect on resistance to deflection fatigue of cast denture clasps Vallitu, P.K. and Miettinen, T. J. Prosthetic Dent. (Mar. 1996) 75, 332-336. International Journal of Fatigue; 1997 Apr;19(4):352. Available from: http://dx.doi.org/10.1016/s0142-1123(97)81069-9

12. Rodrigues RCS, Ribeiro RF, de Mattos M da GC, Bezzon OL. Comparative study of circumferential clasp retention force for titanium and cobaltchromium removable partial dentures. The Journal ofProstheticDentistry;2002 Sep;88(3):290-6. 
Available from:

http://dx.doi.org/10.1067/mpr.2002.128128

13. Reisbick MH, Caputo AA. Influence of loading rates on mechanical properties of cobalt-chromium alloys. Br Dent J; 1975 Apr 15;138(8):2958.Available from: http://dx.doi.org/10.1038/sj.bdj.4803441

14.Dental cobalt chromium casting alloy. BSI British Standards; Available from: http://dx.doi.org/10.3403/30308382u

15. Sato $Y$, Abe $Y$, Yuasa $Y$, Akagawa Y. Effect of friction coefficient on Akers clasp retention. The Journal of Prosthetic Dentistry; 1997 Jul;78(1):22-7. Available from: http://dx.doi.org/10.1016/s00223913(97)70083-0

16. Yuasa Y, Sato Y, Akagawa Nihon Hotetsu Shika Gakkai Zasshi [Internet]. Japan Prosthodontic Society; 1995;39(1):146-52. Available from: http://dx.doi.org/10.2186/iips.39.146

17.McCabe J, Yan Z, Al Naimi O, Mahmoud G, Rolland S. Smart materials in dentistry. Australian Dental Journal; 2011 May 13;56:3-10. Available from: $\quad$ http://dx.doi.org/10.1111/i.1834$\underline{7819.2010 .01291 . x}$

18.Young L, Saplata R. Correctly positioned and soldered wrought wire clasps for removable partial dentures. The Journal of Prosthetic Dentistry;64(2):242-3. Available from: http://dx.doi.org/10.1016/0022-3913(90)90188-i

19. Ahmad I, Sherriff M, Waters NE. The effect of reducing the number of clasps on removable partial denture retention. The Journal of Prosthetic Dentistry [Internet]. Elsevier BV; 1992 Dec;68(6):928-33. Available from: http://dx.doi.org/10.1016/0022-3913(92)90553-m

20.. Frank RP, Nicholls Jl. A study of the flexibility of wrought wire clasps. The Journal of Prosthetic Dentistr;45(3):259-67. Available from: http://dx.doi.org/10.1016/0022-3913(81)90386-3

21. Geramy A, Ejlali M. The curvature of the retentive arm in a circumferential clasp and its effect on the retention: 3D analysis using finite element method. J Indian Prosthodont Soc ; 2007;7(3):118. Available from: http://dx.doi.org/10.4103/0972-4052.37654 